\title{
Social determinants of health and equity
}

The Commission for Social Determinants of Health - CSDH (La Comisión de Determinantes Sociales de la Salud - CSDH) formed in March 2005 by the World Health Organisation (WHO) will deliver its final report towards the middle of 2008. An advance report was presented by CSDH in November 2007; it incorporated contributions from the nine thematic knowledge networks, consisting of investigators from several countries and regions, thereby supporting CSDH's work. Without doubt, such efforts deserve attention and analysis by that part of the academic community addressing matters of public health. A stimulating reading is thus worthwhile.

Achieving Health Equity: from root causes to fair outcomes is the title of CSDH's preliminary report; it has three explicit intentions. It is firstly orientated towards equity (i.e. evaluating inequalities in health from a perspective of justice based on the explicit pattern of the right to enjoy the best level of health possible for living the type of life which people classify as being good). This implicitly stresses the political agreement defined in the WHO's 1948 constitution. Secondly, it attempts to understand the deep causes of inequalities in health amongst social groups within countries, amongst countries and regions of the world. It is aimed at recognising the "causes of the causes," as stated by Michael Marmot, head of the Commission. Thirdly, it issues a call for creating a global movement for equity in health at all possible levels, for achieving just results in health.

An approach to health via social determinants acquires transforming power through its explicit relationship with ensuring equity in health. However, it must not just rest in being simply an academic exercise. It requires sufficient understanding by societies so that the call to ensure the level of health which human dignity demands may be recognised as being a viable goal for all current and future societies. This deals with denaturing the inequalities deriving from people's prestige, wealth or power for jointly constructing the required transformations. This implies affecting matters such as distributing power and wealth amongst regions and countries for globalising benefits and not the negative impacts. It also implies rethinking how efforts are correlated throughout the globalised world and not just rich people's palliative aid for poor people. A regional setting demands alliances and efforts aimed at complementing action regarding such efforts and abilities and not just arrangements regarding commercial exchange. Understanding those mechanisms producing and reproducing inequity within countries is fundamental for reconstructing the political agreements leading to the universality of rights and overcoming the trend towards providing subsides specifically designed for alleviating the lot of poor people.

Recognising that health is socially determined will have advantages concerning the traditional systemic view of risk factors in the sense that the hierarchy of causality resulting from people's social position will be shown up rather than aspects such as individual behaviour. However, this may also become reduced to a list of dislocated variables which cannot get to the root of problems. It will depend on societies' ability to mobilise themselves towards a referent regarding justice recognising human interdependence and dignity. It is not just a technical matter; it is also an ethical-political one.

Mario Hernández, Department of Public Health, Faculty of Medicine, Universidad Nacional de Colombia, Bogota 